\title{
Acknowledgements
}

\section{First Edition}

Anthony Warner read the first draft of this book and offered many valuable comments which have helped me to improve both the organisation of the contents and the explanation of particular points. Jenny Fuchs, although busy with her studies on the second year of the Honours MA in English Language at Edinburgh, gave both a student's reaction and comments worthy of professional linguists. Karin Woodhouse drew my attention to a number of inadequacies. Will Lamb reassured me that the text was at the right level and on the right lines for an introduction to syntax. Over the past ten years a number of classes have acted as guinea pigs for Chapters 6,7 and 8 on clauses and for Chapters 12 and 13 on grammar and semantics (now Chapter 14 on aspect, tense and voice). My thanks to all the above and the usual declaration that I alone am responsible for imperfections.

\section{Second Edition}

The changes which have been made to the first edition have been prompted by my experience in teaching students at the University of Auckland over the last four years. A number of enthusiastic students taking LINGUIST 203 Applied English Grammar - Chinese, Japanese, Korean and New Zealanders - asked searching questions and pointed out typographical errors. The enthusiastic teachers (many of them from the Republic of China) taking LANGTCHG 720 Language Analysis for Teachers explored the analyses and brought interesting and difficult examples to the class to be discussed. I owe a large debt to Keith Montgomery, Andreea Calude and Birgit Karl, dedicated and first-rate tutors with whom I had many productive discussions about the data and analyses. Patricia Marshall has been a superb copy-editor. 